\title{
IMPACT OF TRAFFIC VIBRATION ON THE TEMPLE OF MINERVA MEDICA, ROME: PRELIMINARY STUDY WITHIN THE CO.B.RA. PROJECT
}

\author{
IVAN ROSELLI ${ }^{1}$, VINCENZO FIORITI ${ }^{1}$, IRENE BELLAGAMBA ${ }^{1}$, MARIALUISA MONGELLI ${ }^{1}$, ANGELO \\ TATII $^{1}$, MARIAROSARIA BARBERA ${ }^{2}$, MARINA MAGNANI CIANETTI ${ }^{2}$ \& GERARDO DE CANIO $^{1}$ \\ ${ }^{1}$ ENEA, Italy \\ ${ }^{2}$ Soprintendenza speciale per i Beni Archeologici di Roma, Italy
}

\begin{abstract}
The impact of long-term traffic vibration on ancient structures located in the city centre of big cities is an important issue, as it represents the main factor of fatigue, possibly causing structural damage in historic constructions. This article illustrates the preliminary results of a study on the so-called Temple of Minerva Medica in Rome, Italy, conducted within the CO.B.RA. project, which focuses on the development of advanced technologies and methods for the conservation of cultural heritage assets. The studied monument, which is part of the architectural heritage of ancient Rome, is located very close to several railway tracks just out of the Termini train station, on the north-east side, and to urban tramways, on the west side.

To obtain indications on the dynamic behaviour of the structure and to map the base excitation induced by passing trains and trams, ambient vibration data were acquired by digital recorders with triaxial velocimeters positioned at several measurement points on the ground, around and inside the structure, and at different heights on the north-west façade. For evaluating the structural vulnerability, three-dimensional (3D) architectural surveys and non-destructive investigations on the material properties of the monument were conducted in order to implement a finite element model of the building to be used for structural analyses and dynamic simulations. In particular, to the purpose of obtaining a detailed 3D model, laser scanner and stereo-photogrammetric acquisitions were carried out. Photographic acquisitions were also used to identify the crack pattern and to document the current state of damage. Vibration and 3D reconstruction data were acquired both in summer and in winter, along with thermographic images, for assessing the seasonal effects on the structural behaviour. All collected data were stored into an ad hoc friendly data repository accessible through the internet by the accredited project end-users.
\end{abstract}

Keywords: 3D reconstruction, ancient Roman masonry, dynamic identification, non-destructive tests, traffic vibration

\section{INTRODUCTION}

In the maintenance of architectural heritage in contemporary urban environments, a significant issue is the impact of vibrations that may affect the integrity and conservation of historic buildings. This aspect is particularly important in southern European countries, namely in Italy, where the concentration of historical and monumental buildings in urban areas is the greatest worldwide, as documented by UNESCO [1].

In order to understand the potential impact of vibrations on the buildings, an appropriate characterization of materials and structural behaviour is crucial. This knowledge can be gained through a series of material characterization techniques. In particular, three-dimensional (3D) architectural surveys and non-destructive tests (NDTs) on the material properties of the monument can be carried out in order to implement a numerical model of the building. Such numerical models can be used for structural analyses and dynamic simulations that can provide accurate results demonstrating the stress state of the building and possible failure mechanisms affecting its stability. 
This article will illustrate the preliminary results of a study on the so-called Temple of Minerva Medica in Rome, Italy. This study was conducted within the CO.B.RA project [2], which focuses on the development of advanced technologies and methods for the conservation of cultural heritage assets. The main focus of the study will be on the measurements and analysis of the vibrations data. To map the base excitation induced by passing urban vehicles vibrations data were recorded at several measurement points on the ground, around and inside the structure. As particular importance is related to the dynamic behaviour aiming to provide an assessment of the vulnerability of the building, vibration data were also acquired at different heights on the north-west façade.

\section{TRAFFIC VIBRATIONS AND HISTORICAL BUILDINGS}

The vibration sources in contemporary urban areas are mostly related to transportation infrastructures, such as road traffic, metro systems, urban railroads and tramways. In some cases, there are also other relevant vibration sources mainly related to construction activities and crowded events.

Vibrations are transmitted through the ground to building foundations and from foundations to the upper structure, representing the main factor of fatigue, possibly causing structural damage in vulnerable constructions, such as most historic buildings and monuments. Therefore, the study of this phenomenon has received significant attention by conservationists, scientists and engineers in the last several decades. Also lawmakers or regulatory agencies of many different countries have released various standards to limit the intensity of vibrations that human activities and transportation systems are allowed to release to environment, especially close to the most vulnerable structures.

In the literature, many recent experimental and theoretical studies aimed at characterizing the vibratory phenomena caused by traffic, construction activities, explosions and their effects on buildings can be found, as reported in Refs. [3-8]. More specifically, several researchers studied the effects that external sources of vibration may produce on historical buildings that represent a significant architectural heritage. An interesting discussion on this subject can be found in Ref. [9] outlining that a distinction shall be made between short-term and long-term effects, as the latter could gradually produce damages also for very low vibration intensities and that degradation phenomena due to long-term vibrations are not well known. This is particularly important for historic buildings that may not be structurally sound and material degradation may already have been taking place for other reasons. On the other hand, even small damages, such as just cosmetic damages, may be very significant for both monetary and non-monetary values, when dealing with architectural heritage.

Long-term vibrations are usually associated with traffic in urban roads. Some relevant studies reported the impact of traffic vibrations on monumental buildings in Rome, in which longterm vibrations have been clearly associated with damages (Clemente and Rinaldis [10]), and disclosing of damages in the long run and eventually correlating damages to low-intensity steady vibrations have been indicated (Pau and Vestroni [11]).

Moreover, the frequent transit of heavy vehicles, trains and trams very close to a structure may induce vibrations largely exceeding the intensity of those caused by normal traffic and therefore may be responsible for damages beyond cosmetic level and also involving secondary or main structural components. Careful monitoring of such phenomena is very important for the protection of architectural heritage buildings.

While numerous studies have been made on the vibration caused by railways (Kouroussis et al. [12]), very little research has been carried out on similar problems caused by trams. The 
two transport systems are conceptually similar, but there are significant differences in terms of infrastructure (tramways are mostly located along roadways shared with other traffic), vehicles (different mass and length of the vehicles) and speed (the speed of trams is normally much lower), as highlighted by Pronello [13]. In Refs. [14-18] some authors reported that vehicle dynamics influence the low-frequency range (up to about $15 \mathrm{~Hz}$, but the upper limit of this low-frequency range is not well defined and depends on the main vehicle dynamic modes). In the frequency range from this limit up to about $100 \mathrm{~Hz}$ the ground vibration spectrum is characterized by the track and soil flexibility, with possible soil resonance.

The impact of light transit vehicles, like trams or metros, is very important due to the close distance between the track and the buildings. Such vehicles are characterized by a low speed and a relatively high density of singular rail surface defects, like rail joints, rail crossings or even simple necessities like switching gears. Recent studies [19, 20], which focused on the T2000 tram circulating in Brussels, after receiving a large number of complaints about vibrations, analysed the effects of tram vehicle characteristics and the quality of rail surface on ground vibrations.

\section{VIBRATION STANDARDS}

The relevance of population disturbance and potential impact on the structural health caused by vibrations in urban areas led to the development of several standards in different countries to set limits to the vibration intensities recorded at significant reception points in buildings. Current standards give indications on the methods that must be used for the measurement procedure, including the proper choice of type and location of the instrumentation, as well as the measurement data processing and analysis. In most standards, the key parameter considered for assessing the intensity of vibration is the peak particle velocity (PPV), that is the maximum value of vector velocity recorded in triaxial acquisitions. Alternatively, other standards consider the peak component particle velocity (PCPV), which is simply the maximum value of velocity recorded in each triaxial direction.

Vibration limits are stated for various ranges of the dominant excitation frequencies and different building types, having different structural characteristics, among which historic structures are usually the ones with the lowest limits.

An international widely accepted standard for the measuring of vibrations in buildings is the ISO 4866 standard [21]. National standards generally comply with ISO 4866 in terms of procedures. Nonetheless, national limits of acceptability may differ substantially, especially the ones concerning ancient buildings, as the structural characteristics of this kind of buildings are very different from one country to another. Some standards are based on experimental campaigns performed on typical buildings, while some others refer to limits stated in other countries. For example, the recently revised Italian UNI 9916 [22] includes as reference several foreign standards. Among them, the German DIN 4150 and the Swiss SN 640312 (a) state specific limits for historic buildings [23, 24].

The DIN 4150 proposes different limits for short-duration and for long-term vibrations in terms of PCPV and is considered to be conservative also for the typical historical buildings existing in Italy. The short-duration vibrations are defined as the vibrations that do not cause fatigue and resonance phenomena in the structure. On the opposite, if these phenomena cannot be excluded, then long-term limits must be considered. Consequently, such distinction depends on the structural characteristics of the studied building. 
Similarly, the SN 640312 (a) proposes PPV limits with different frequency ranges and with a distinction in occasional, frequent and permanent vibrations. In case of historic buildings the Swiss standard suggests that PPV limits are halved.

Many other international standards and recommendations exist, most of which indicate different limits for short-term and long-term vibrations, although they are variously defined (see [25-29]). In general, long-term limits, which are mostly related to urban traffic vibrations, are stricter, as they might generate fatigue and resonance problems in the structures in the long run. Ultimately, as a general indication, most of current international standards and recommendations suggest that long-term vibration intensity at historic buildings should be limited to PPV or PCPV values below $2-3 \mathrm{~mm} / \mathrm{s}$.

\section{THE STUDIED STRUCTURE}

The so-called Temple of Minerva Medica is an ancient ruined building in the city centre of Rome. Starting from the 16th century, it was erroneously thought to be a temple dedicated to Minerva Medica ('Minerva the Doctor') mentioned by Cicero and other sources, so that it is still today widely known through such appellation.

In fact, more recently, archaeologists believe it is what remains of an ancient nymphaeum (a building devoted to the nymphs and often connected to the water supply) of Imperial Rome (early 4th century AD), on the Esquiline Hill, between the Labicana and Aurelian Walls, probably part of the Horti Liciniani, but attribution is still discussed (Barbera et al. [30]). More precisely, it is located in modern Via Giolitti, where, in the early 20th century, urban tramways were built very close to the west side of the monument (Fig. 1a) and are still active today. Moreover, a few metres from the building to the north-east are several railway tracks of the nearby Termini train station. Railway tracks exist there since the mid-19th century, when the Rome-Frascati railway line, the oldest in Rome, was built by the Papal State (Panconesi [31]).

The structure is a majestic building with decagonal polylobate plan, a diameter of $25 \mathrm{~m}$ and an overall height originally of $32 \mathrm{~m}$, currently reduced to only $24 \mathrm{~m}$ after the dome partial collapses during the centuries. The façade with the main entrance is on the north-west side (Fig. 1b).

The initial structure (built around 300 AD) was entirely made up of opus latericium, but soon presented structural problems and was restored and reinforced through works in opus mixtum of tuff bricks and Roman bricks (Fig. 2a and 2b). Lateral niches were closed and

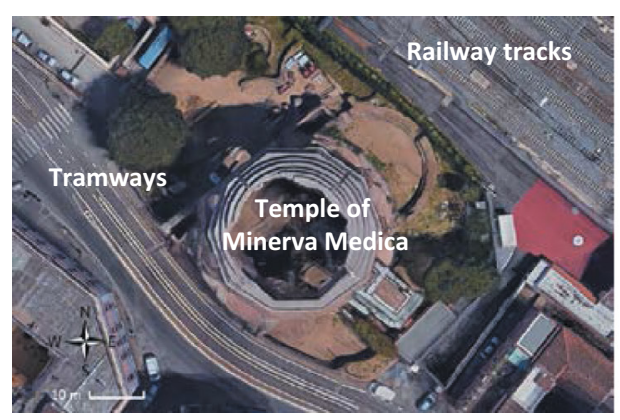

(a)

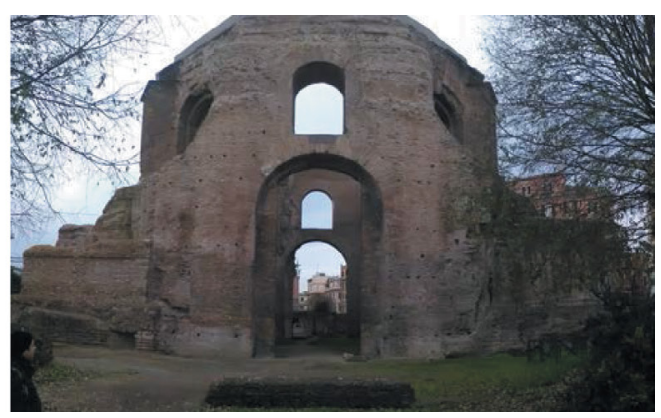

(b)

Figure 1: Aerial photograph of the temple of Minerva Medica (a). Façade on the north-west side of the monument (b). 


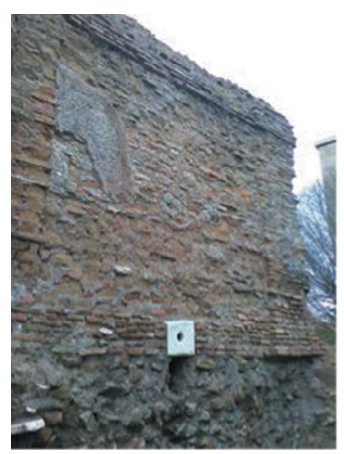

(a)

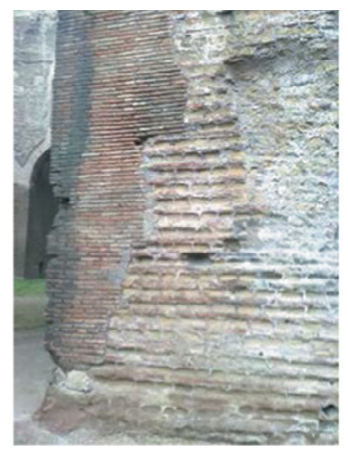

(b)

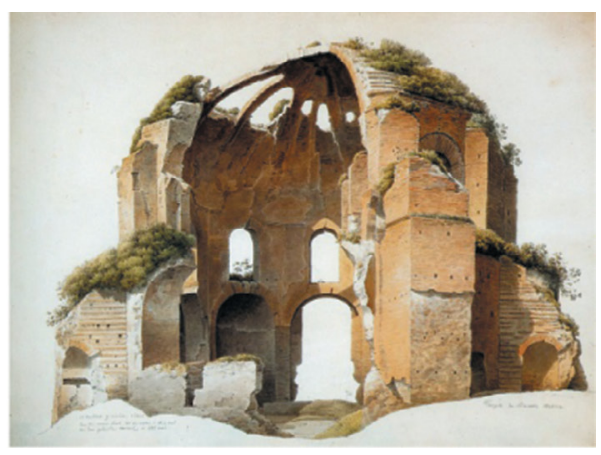

(c)

Figure 2: Masonry of a wall (a) and a pillar (b) on the north side. A painting by Josephus Augustus Knip, 1809-1812, showing a view from south of the monument (c).

walls with the function of buttresses were built (Barbera et al. [30]). In fact, the current masonry results are quite heterogeneous in materials and shapes.

This is evidence of several changes of mind during the construction phases and of the various collapses and restoration works executed during the centuries. In particular, structural damages in the past concentrated on the south side (Fig. 2c), where a recent major restoration intervention was conducted in 2012-2013. In that occasion studies and surveys were carried out, highlighting that foundation properties on the south side were mainly responsible for the damages rather than structural weakness of the masonry in that part of the building (Barbera et al. [30]).

\section{EXPERIMENTAL DATA ACQUISITION}

The acquisition of several types of experimental data was scheduled starting from July 2016. All measurements were planned to be repeated during a period of one year in order to investigate the seasonal effects and/or the eventual changes in the structural response of the building. For such purpose also weather data were collected for correlation to experimental data. The experimental programme can be summarized as follows:

- Ambient vibration data.

- NDTs (thermal images, sonic tomography).

- Microclimatic monitoring (air temperature, humidity, air pressure, etc.).

- Surveys for detailed 3D reconstruction and crack pattern documentation (3D laser scanning and stereo-photogrammetric survey).

\subsection{Ambient Vibration Data Acquisition}

Ambient vibration data were acquired on 4 July. The measurements at the foundations (Fig. $3 \mathrm{a}$ and $3 \mathrm{~b}$ ) were intended to obtain indications on the points where base excitation due to the nearby traffic (road, trains and trams) is stronger. The data recorded on the façade helped assess the amplification to the structure and the dynamic behaviour of the building (Fig. 4). Vibration data were acquired by digital recorders equipped with triaxial velocimeters provided with a Global Positioning System antenna for time synchronization. The sensors were oriented so as to measure the radial (towards the centre of the decagonal hall), the 


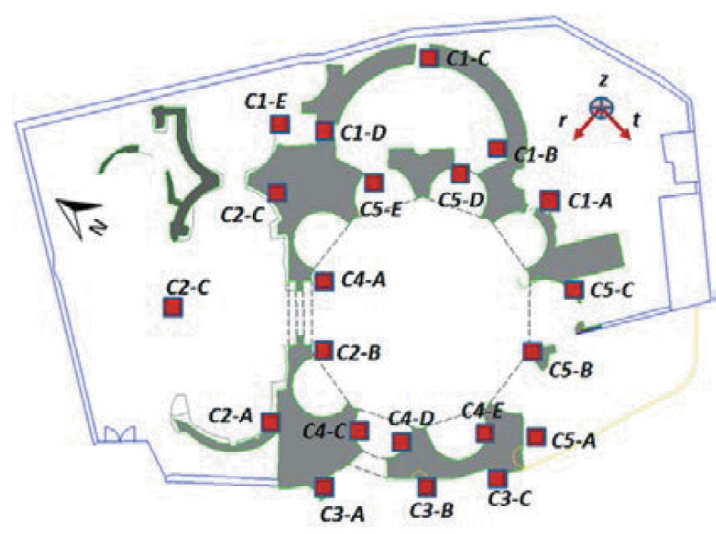

(a)

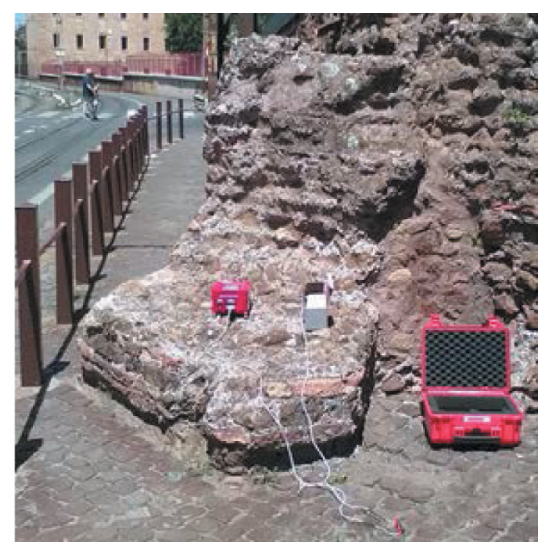

(b)

Figure 3: Measurement points at the monument foundations (a). Recorded components are $r$ for radial (towards the centre of the hall), $t$ for tangential and $z$ for vertical. Ambient vibration acquisition at position $\mathrm{C} 3-\mathrm{A}$ on the west side (b).

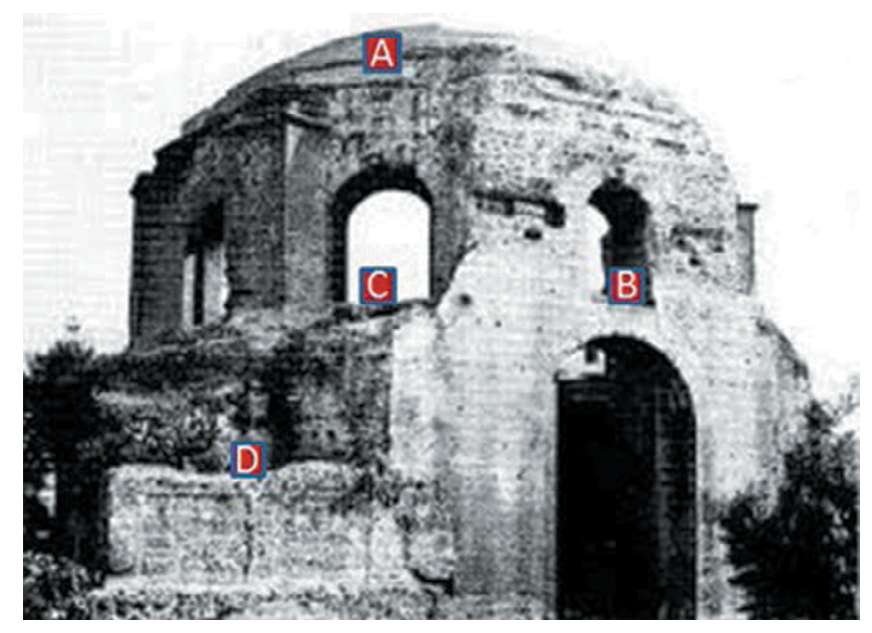

Figure 4: Measurement points on the façade.

tangential and the vertical components, named $r, t$ and $z$, respectively, in the following. Each position was acquired for at least $20 \mathrm{~min}$ at a sampling frequency of $200 \mathrm{~Hz}$. During vibration acquisition, the time and type of vehicle passages were also noted.

\subsection{Non-destructive Tests}

Thermal images of the inner side of walls of the monument were captured on 5 August 2016 at 11 a.m. and on 20 December 2016 at 2 p.m. using a Flir T440 thermal infrared camera. Figure 5 shows a thermal image with the corresponding photograph of a portion of the south side acquired on 5th August. 


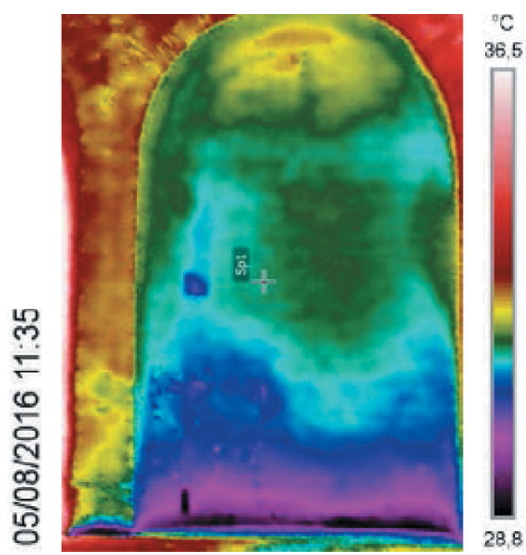

(a)

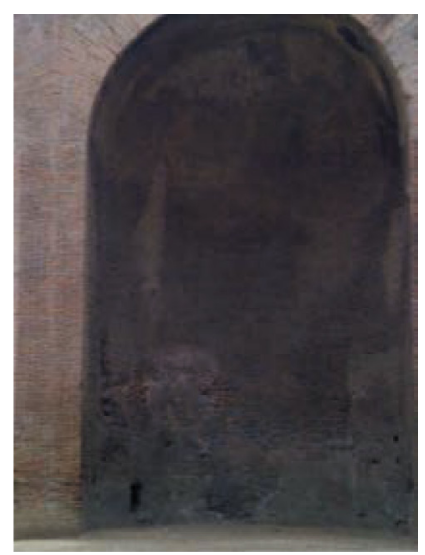

(b)

Figure 5: Thermal image of a portion of south inner side acquired on 5 August 2016 at 11:35 local time (a) and related photograph (b).

A sonic tomography survey was carried out on 2 February 2017. The base of each pillar of the monument was investigated with direct sonic measurements in order to detect the internal morphology of structural elements. This technique is especially useful for investigating heterogeneities in construction materials, such as historic masonry, allowing the identification of layering of the sections, the presence of voids, cavities and anomalies in material density. Equipment comprised an instrumented hammer with a PCB ICP accelerometer, as well as the probe, both cabled to the acquisition unit. Data were acquired with a sampling frequency of $500 \mathrm{kHz}$.

\subsection{Microclimatic Parameters}

Microclimatic parameters and data of local weather stations were collected for correlation to experimental ambient vibration and NDT data. In particular, air temperature and humidity were monitored by two MSR145 mini-data loggers positioned on the west side (near C4-C) and on the east side (near C5-D).

\subsection{Three-Dimensional Reconstruction and Crack Pattern}

Two 3D laser scanning surveys were performed on 5 August 2016 and on 20 December 2016 using a Riegl Z360 equipped with a Nikon D100 digital camera. The instrument nominal angular resolution is $0.0025^{\circ}$ horizontal and $0.002^{\circ}$ vertical, while range accuracy can achieve $+/-6 \mathrm{~mm}$. Retroreflecting targets fixed at each pillar at the height $2.5 \mathrm{~m}$ from the ground level were used as reference positions in order to compare the two obtained 3D reconstructions. Also a photogrammetric survey was carried out, comprising about 500 digital images (5 MB and $10 \mathrm{Mpx}$ each), acquired by Nikon D60 camera.

The above acquired images were post-processed with Structure from Motion (SfM) methodology (Mongelli et al. [32]) by Agisoft PhotoScan software via ENEAGRID, available on Computational Research Center for Complex Systems High Performance Computing (HPC) infrastructure (Ponti [33]). A dense cloud of 30 million points was obtained and mesh returned more than 200,000 tria elements (Fig. 7). Stereo-photogrammetry by SfM is complementary 


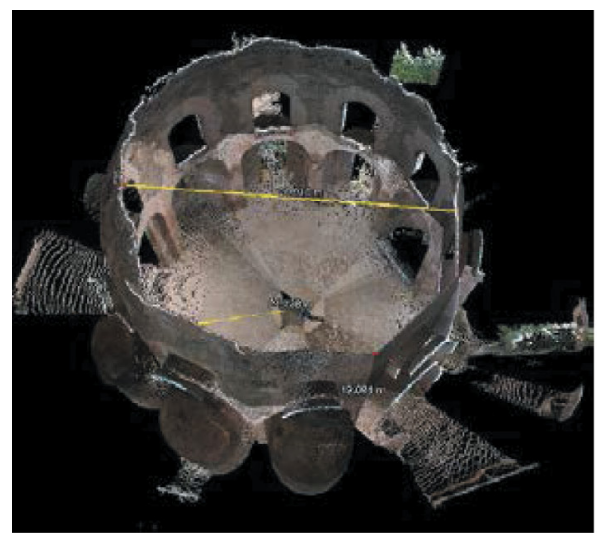

(a)

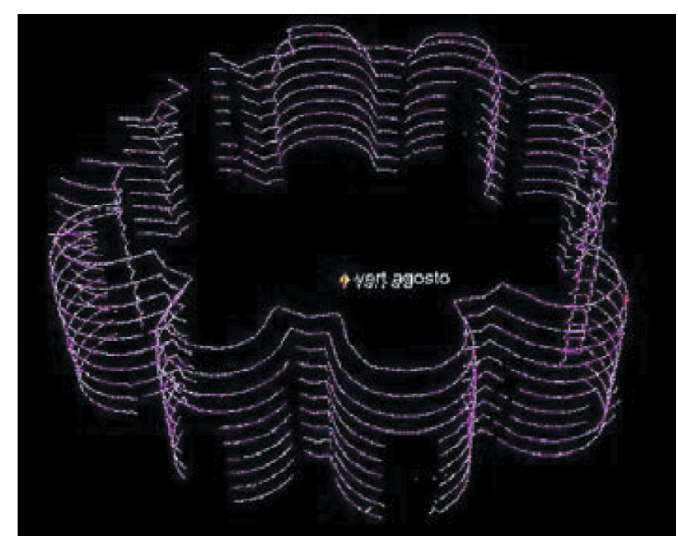

(b)

Figure 6: Three-dimensional laser scanner reconstruction in August (a) and matching between August (white mesh) and December (purple mesh) reconstructions (b).

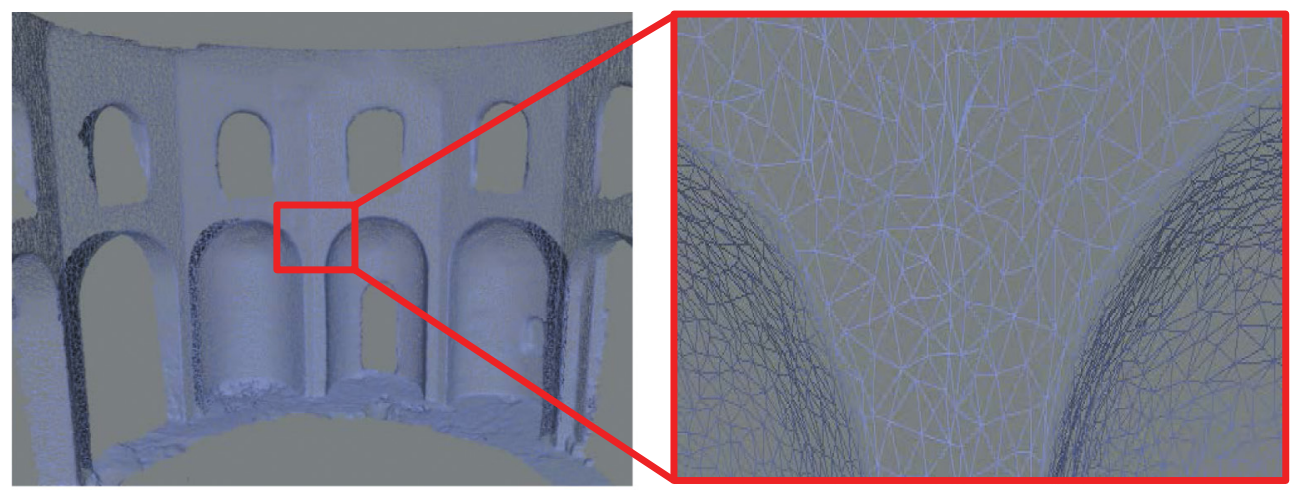

(a)

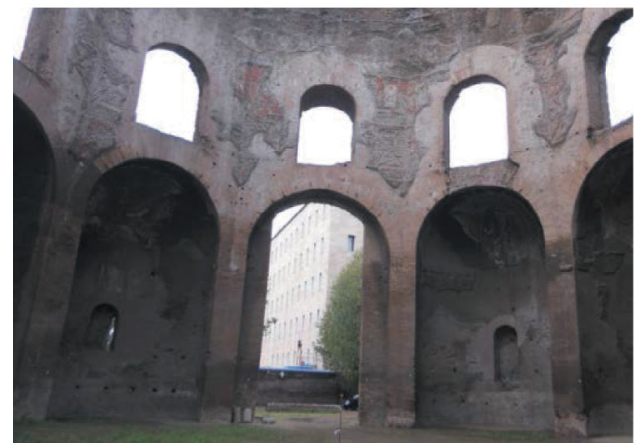

(b)

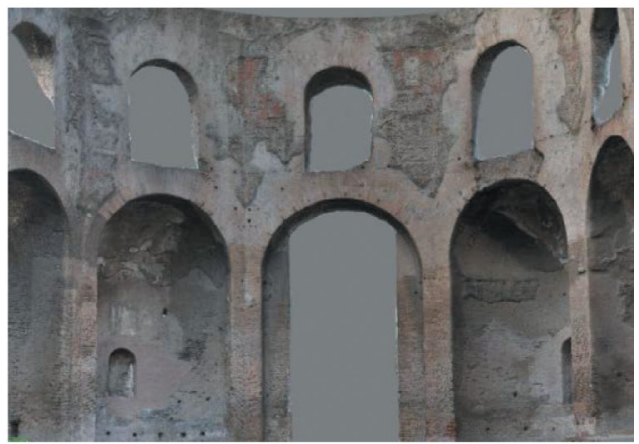

(c)

Figure 7: Three-dimensional reconstruction by SfM technique: mesh with tria elements of west side and enlargement of the area in the red box (a); comparison between a 2D image (b) and related 3D texture (c) of south side. 
to laser scanning, since it is less accurate in 3D geometry reconstruction but is able to provide detailed crack pattern documentation.

\section{VIBRATION DATA ANALYSES}

First, a visual analysis of velocity time-histories was carried out, trying to match vibrations with vehicle passages, according to their recorded time, in order to interpret what kind of source generated each recognizable vibration greater than instrumental noise. Traffic sources were classified as road, trains and trams. Each source was characterized in the frequency domain by simple fast Fourier transform.

Second, PPV and PCPV values were calculated. The highest values were considered as indication of the most critical points at the foundations.

Data acquired on the façade were also processed for structural dynamic identification of the building. A variety of experimental and operational modal analysis (OMA) techniques were considered, in order to have mutual validation of results and obtain more solid values of modal parameters. In particular, the frequency response function (FRF) was calculated using the transmissibility function H (De Silva [34]) between foundation wall (D) and windows (B and C), as well as between foundation wall and top (A) of the façade. Among the various OMA techniques the frequency domain decomposition (FDD), the enhanced frequency domain decomposition (EFDD) and the Crystal Clear Subspace Stochastic Identification algorithms were applied (De Canio et al. [35]). Finally, also the horizontal vertical spectral ratios (HVSR) were calculated at windows and on top of the façade, providing a further empirical estimate of fundamental frequencies of the building (Gallipoli et al. [36]).

\section{PRELIMINARY RESULTS}

The acquired velocity time-histories revealed the different properties of the vibrations generated by each type of traffic source (Fig. 8). Common road traffic originated vibrations with PCPV lower than $0.2 \mathrm{~mm} / \mathrm{s}$ in all acquisitions. Recorded train passages gave higher vibration

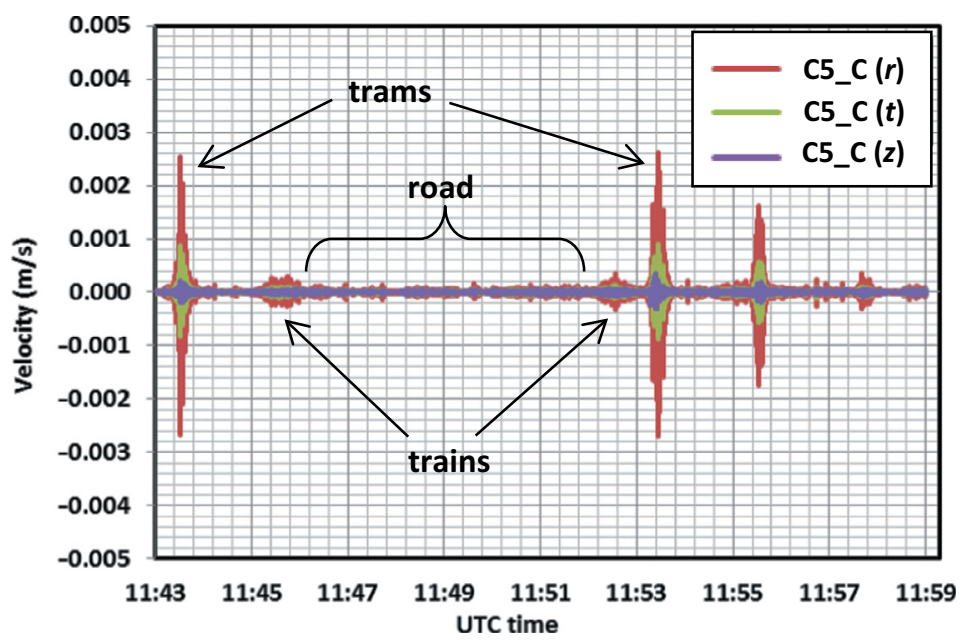

Figure 8: Recorded velocity time-history at position C5-C. The passages of the various traffic sources are indicated (road, trams and trains). 
levels, but PCPV was never greater than $0.4 \mathrm{~mm} / \mathrm{s}$. Train and tram passages produced similar values of peak velocity on the north-east side, near the railway tracks. In all other positions, tram passages induced the strongest vibrations. In particular, the highest PCPV values were recorded in C5-C and C3-A (2.7 and $2.2 \mathrm{~mm} / \mathrm{s}$, respectively) and in several other positions $\mathrm{PCPV}$ was higher than $1 \mathrm{~mm} / \mathrm{s}$.

Tram and train passages were also characterized in terms of duration and fundamental frequencies. Typical duration of tram passages resulted around 15-20 s, while train passages were generally remarkably longer (40-50 s). As shown in Figure 9, the fundamental frequencies of vibrations induced by trams and trains resulted quite similarly ( 35 and $37 \mathrm{~Hz}$, respectively, at the most critical position $\mathrm{C} 5-\mathrm{C}$ ).

The results in terms of modal frequencies obtained with the several considered modal analysis techniques are illustrated in Table 1 . The identified modal frequencies are very similar using all the applied techniques, giving evidence of the consistency and affordability of the results (mutual validation).

The first five modal frequencies resulted within $5 \mathrm{~Hz}$ that are much lower than the fundamental frequencies of traffic vibrations. As confirmed by the vibrations recorded at the windows and on top of the façade, which do not show any relevant amplification effect, resonance phenomena are very limited.

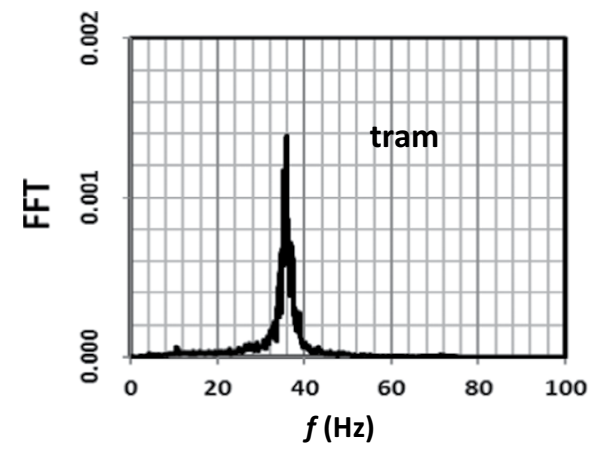

(a)

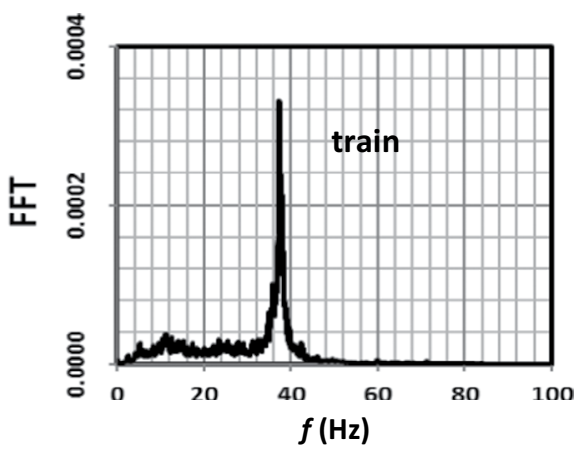

(b)

Figure 9: Fast Fourier transform (FFT) of recorded vibration velocity originated by the passage of a tram (a) and a train (b) at position C5-C.

Table 1: Modal frequencies calculated with each used modal analysis technique.

\begin{tabular}{cccccccc}
\hline \multirow{2}{*}{ Mode } & \multicolumn{7}{c}{ Modal frequencies (Hz) } \\
\cline { 2 - 8 } & FRF (r) & FRF (t) & HVSR (r) & HVSR (t) & FDD & EFDD & CC-SSI \\
\hline 1 & 2.1 & 2.1 & 2.1 & 2.1 & 2.1 & 2.1 & 2.1 \\
2 & 2.8 & - & 2.5 & - & 2.5 & 2.5 & 2.5 \\
3 & - & 2.9 & - & 2.8 & 2.8 & 2.8 & 2.8 \\
4 & - & 3.8 & - & 3.6 & 3.6 & 3.6 & 3.6 \\
5 & 4.1 & - & 4.2 & - & 4.2 & 4.1 & 4.1 \\
\hline
\end{tabular}


In August, wall temperatures varied from 28 to $43^{\circ} \mathrm{C}$, with maximum values on the upper south-west side. In December, temperatures distribution was much more uniform (from 8 to $11^{\circ} \mathrm{C}$ ). A preliminary estimation of the thermal effect on the monument was calculated considering a coefficient of thermal expansion of $5 \times 10^{-6}{ }^{\circ} \mathrm{C}^{-1}$. As an example, the width of the building main entrance at the façade was estimated to increase of about $1 \mathrm{~cm}$ in December. This estimation was compared with results from 3D laser scanner data, which gave a measured width increase of $11 \mathrm{~mm}$ in December (estimated precision of $0.4 \mathrm{~mm}$ ), which is very similar to the estimated effect of thermal expansion.

\section{CONCLUSIONS}

In this article, the preliminary results of a study about the impact of traffic vibrations on the so-called temple of Minerva Medica are described. The relevance of the various traffic vibration sources was assessed. While the road traffic seemed not to represent a dangerous source of vibrations, the vibrations induced by the tram passages in Via Giolitti produced remarkable PCPV values in some points of the foundations, especially on the south and the west sides of the monument. Consequently, as a preliminary indication, the south side, where the monument suffered serious structural problems during his history, and the west side, which is the closest to the tramway tracks, result in the most critical points.

Through the mutual validation of the numerous applied modal analyses, although calculated with very few measurement points, very solid indications of the fundamental frequencies of the building were obtained. Such indications will be used for the calibration of numerical models that will be produced from the acquired 3D reconstruction and NDT data.

\section{REFERENCES}

[1] UNESCO website, http://whc.unesco.org/en/statesparties/it

[2] CO.B.RA. project website, http://cobra.enea.it/english

[3] Athanasopuolos, G.A. \& Pelekis, P.C., Ground vibrations from sheetpile driving in urban environment: measurements, analysis and effects on buildings and occupants. Soil Dynamics and Earthquake Engineering, 19, pp. 371-387, 2000. DOI: 10.1016/ S0267-7261(00)00008-7.

[4] Hunaidi, O., Guan, W. \& Nicks, J., Building vibrations and dynamic pavement loads induced by transit buses. Soil Dynamics and Earthquake Engineering, 19, pp. 435-453, 2000. DOI: 10.1016/S0267-7261(00)00019-1.

[5] Xu, Y.L. \& Hong, X.J., Stochastic modelling of traffic-induced building vibration. Journal of Sound and Vibration, 313, pp. 149-170, 2008. DOI: 10.1016/j.jsv.2007.11.031.

[6] Singh, P.K. \& Roy, M.P., Damage to surface structures due to blast vibration. International Journal of Rock Mechanics \& Mining Sciences, 47, pp. 949-961, 2010. DOI: 10.1016/j.ijrmms.2010.06.010.

[7] Albert, D.G., Taharzadeh, S., Attenborough, K. \& Boulanger, P., Ground vibrations produced by surface and near-surface explosions. Applied Acoustics, 74, pp. 1279-1209, 2013. DOI: 10.1016/j.apacoust.2013.03.006.

[8] Lopes, P., Alves Costa, P., Ferraz, M., Calçada, R. \& Silva Cardoso, A., Numerical modelling of vibrations induced by railway traffic in tunnels: From the source to nearby buildings. Soil Dynamics and Earthquake Engineering, 61-62, pp. 269-285, 2014. DOI: 10.1016/j.soildyn.2014.02.013.

[9] Rainer, J.H., Effect of vibrations on historic buildings: An overview. The Association for Preservation Technology Bulletin, 15, pp. 2-10, 1982. DOI: 10.2307/1494019. 
[10] Clemente, P. \& Rinaldis, D., Protection of a monumental building against trafficinduced vibrations. Soil Dynamics and Earthquake Engineering, 17, pp. 289-296, 1998. DOI: 10.1016/S0267-7261(98)00012-8.

[11] Pau, A. \& Vestroni, F., Vibration assessment and structural monitoring of the Basilica of Maxentius in Rome. Mechanical Systems and Signal Processing, 41, pp. 454-466, 2013. DOI: 10.1016/j.ymssp.2013.05.009.

[12] Kouroussis, G., Connolly, D.P. \& Verlinden, O., Railway-induced ground vibrations - a review of vehicle effects. International Journal of Rail Transportation, 2(2), pp. 69-110. DOI: 10.1080/23248378.2014.897791.

[13] Pronello, C., Analysis of Tram-induced vibrations affecting roads and buildings in standard urban sites. International Journal of Acoustics and Vibration, 8(1), pp. 21-29, 2003. DOI: 10.20855/ijav.2003.8.1126.

[14] Alias, J., La voie ferrée - technique de construction et d'entretien, 2nd ed., Paris: Eyrolles (in French), 1984.

[15] Heckl, M., Hauck, G. \& Wettschureck, R., Structure-borne sound and vibration from rail traffic. Journal of Sound and Vibration, 193(1), pp. 175-184, 1996. DOI: 10.1006/ jsvi.1996.0257.

[16] Dahlberg, T., Railway track dynamics - a survey, Technical Report Railtrdy.doc/200311-06/td., Linköping University, Sweden.

[17] Kouroussis, G., Verlinden, O. \& Conti, C., Influence of some vehicle and track parameters on the environmental vibrations induced by railway traffic. Vehicle System Dynamics, 50(4), pp. 619-639, 2012. DOI: 10.1006/jsvi.1999.2647.

[18] Kouroussis, G., Conti, C. \& Verlinden, O., Investigating the influence of soil properties on railway traffic vibration using a numerical model. Vehicle System Dynamics, 51(3), pp. 421-442, 2013. DOI: 10.1080/00423114.2012.734627.

[19] Kouroussis, G., Verlinden, O. \& Conti, C., On the interest of integrating vehicle dynamics for the ground propagation of vibrations: The case of urban railway traffic. Vehicle System Dynamics, 48(12), pp. 1553-1571, 2010. DOI: 10.1080/00423111003602392.

[20] Kouroussis, G., Verlinden, O. \& Conti, C., Contribution of vehicle/track dynamics to the ground vibrations induced by the Brussels tramway. Sas P, Bergen B, editors. ISMA2010 International Conference on Noise and Vibration Engineering; Sept 20-22; Leuven. Leuven: ISMA; 2010; p. 3489-3502.

[21] ISO 4866, Mechanical vibration and shock vibration of buildings. Guidelines for the measurement of vibrations and evaluation of their effects on buildings, 2010.

[22] UNI 9916, Criteri di misurazione e valutazione degli effetti delle vibrazioni sugli edifice, (in Italian), 2014, Italian standard.

[23] DIN 4150, Erschütterungen im Bauwesen - Einwirkungen auf baulichen Anlagen, (in German), 2015, German standard.

[24] SN 640312 a, Effet des ébranlements sur les constructions, (in French), 1992, Swiss standard.

[25] Ministère de l'Environnement, de l'Energie et de la Mer, Circulaire du 23/07/86 relative aux vibrations mécaniques émises dans l'environnement par les installations classées pour la protection de l'environnement, (in French), 1986, French standard.

[26] Whiffen, A.C., A survey of traffic-induced vibrations. (Report LR419.), 1971, United Kingdom Department of Environment, Road Research Laboratory, Crowthorne, UK.

[27] American Association of State Highway and Transportation Officials, Standard recommended practice for evaluation of transportation - related earthborne vibrations, 1990, Washington, DC. 
[28] Konon, W., Vibration criteria for historic buildings. Journal of Construction Engineering and Management, 111(3), pp. 208-215, 1985. DOI: 10.1061/(ASCE)0733-9364

[29] Wiss, J.F., Construction vibrations: state-of-the-art. Journal of the Geotechnical Division, 107(2), pp. 167-181, 1981.

[30] Barbera, M., Magnani Cianetti, M. \& Barrano, S., Da Massenzio a Costantino: le indagini in corso nel c. d. tempio di Minerva Medica. Proceedings of the International Conference of CISEM - La villa restaurata e $i$ nuovi studi sull'edilizia residenziale tardoantica, Piazza Armerina, Italy, (in Italian), 2014.

[31] Panconesi, M., Le ferrovie di Pio IX, (in Italian), ed. Calosci-Cortona, Calosci, Cortona, Italy, 2005.

[32] Mongelli, M., De Canio, G., Roselli, I., Malena, M., Nacuzi, A. \& De Felice, G., 3D photogrammetric reconstruction by drone scanning for FE analysis and crack pattern mapping of the 'bridge of the towers', Spoleto. Key Engineering Materials, 747, pp. 423-430, Bologna, Italy, 2017.

[33] Ponti, G., Palombi, F., Abate, D., Ambrosino, F., Aprea, G., Bastianelli, T., Beone, F., Bertini, R., Bracco, G., Caporicci, M., Calosso, B., Chinnici, M., Colavincenzo, A., Cucurullo, A., D’Angelo, P., de Rosa, M., de Michele, P., Funel, A., Furini, G., Giammattei, D., Giusepponi, S., Guadagni, R., Guarnieri, G., Italiano, A., Magagnino, S., Mariano, A., Mencuccini, G., Mercuri, C., Migliori, S., Ornelli, P., Pecoraro, S., Perozziello, A., Pierattini, S., Podda, S., Poggi, F., Quintiliani, A., Rocchi, A., Sciò, C., Simoni, F., Vita, A., The role of medium size facilities in the HPC ecosystem: The case of the new CRESCO4 cluster integrated in the ENEAGRID infrastructure. Proceedings of the International Conference on High Performance Computing and Simulation (HPCS) Bologna, Italy, 2014.

[34] De Silva, C.W., Vibration and Shock Handbook, CRC Press, Boca Raton, Florida, USA, 2005.

[35] De Canio, G., Mongelli, M., Roselli, I., Tatì, A., Addessi, D., Nocera, M. \& Liberatore, D., Numerical and operational modal analyses of the 'Ponte delle Torri', Spoleto, Italy. Proceedings of the 10th International Conference on Structural Analysis of Historical Constructions (SAHC), pp. 752-758, 2016.

[36] Gallipoli, M.R., Mucciarelli, M. \& Vona, M., Empirical estimate of fundamental frequencies and damping for Italian buildings. Earthquake Engineering \& Structural Dynamics, 38(8), pp. 973-988, Leuven, Belgium, 2009. DOI: 10.1002/stc.277. 